\title{
A Comparative Retrospective Study of Lipid Profile in Obese Type 2 Diabetics and Obese Non Diabetics in Aseer Region, K.S.A.
}

Awad S. Alsamghan

Family \& Community Medicine Department, College of Medicine, King Khalid University, Abha, Kingdom of Saudi Arabia

Correspondence:

Dr. Awad S. Alsamghan

Family \& Community Medicine Department, College of Medicine, King Khalid University, P.O. Box 641, Abha, Kingdom of Saudi Arabia

Contact No.: +966503750084

Email: awadalsamghan@gmail.com

Received September 2020. Accepted October 2020. Published November 1, 2020.

Please cite this article as: Awad S. Alsamghan.A Comparative Retrospective Study of Lipid Profile in Obese Type 2 Diabetics and Obese Non Diabetics in Aseer Region, K.S.A. Middle East J Intern Med 2020; 13(2): 3-12. DOI: 10.5742/MEJIM2020.93783

\section{ABSTRACT}

Background: There is an increase in the prevalence of obesity all over the world. It has become a serious problem as it leads to several other metabolic chronic disorders including Diabetes mellitus (DM), one of the major global pandemics nowadays. Obesity and DM are currently threatening health, wellbeing and welfare of humans. They have a close relationship, and type 2 diabetes mellitus (T2DM) is strongly associated with obesity. T2DM is a common disorder known to everybody, with a prevalence that usually rises with increasing degrees of obesity. Dyslipidemia is found high in patients with diabetes mellitus and obesity. There is increasing evidence that abnormal changes in the metabolism of lipids are amazingly very important risk factors of diabetes leading to many complications. The most important complications are lipid profile abnormalities which are a good indicator for risk (risk factor). Abnormalities in the serum lipid levels are most likely to participate to the increased risk of coronary artery diseases in patients with diabetes. The Aim of this study is to assess the correlation between serum lipid profile as a risk factor for cardiovascular disease with other biochemical/hormonal variables, anthropometric and clinical variables among obese diabetes mellitus and obese non-diabetic patients.
Methods: A comparative retrospective cross sectional study of obese type 2DM and obese non-diabetic patients was conducted at the Family Medicine Department, College of Medicine, King Khalid University, Abha, Saudi Arabia through data provided by the Medical Specialist Center in Abha city and Diabetes and endocrine Centre which belong to Khamis Mushait Military Hospital from March 2020 to May 2020. A total of 500 Saudi participants (200 obese Type 2 diabetic patients (T2DM) [Group I], 200 obese non-diabetic patients [Group II] and 100 healthy controls [Group III]) were randomly selected using systematic random sampling technique to assess the association of dyslipidemia and other biochemical/hormonal variables as risk factors in obese T2DM and obese non-diabetic patients. Fasting venous blood sample was collected. Patients were subjected to investigations of fasting blood sugar, glycosylated hemoglobin (HbA1c), fasting serum lipids profile, kidney function tests, liver enzymes, thyroid function tests and vitamin D level. Anthropometric and clinical variables among obese diabetes mellitus and obese non-diabetic patients were evaluated. Statistical analysis was carried out using standard deviation and chi-square from which ' $p$ ' value is derived. Independent sample ttest was used to compare means. $P$-value $<0.05$ was considered statistically significant. 
Results: In the obese diabetic patient group (GI) and obese non-diabetic patient group (GII), the mean total cholesterol levels, triglycerides levels, LDL-C levels were found to be [TC $=\mathbf{2 1 0 . 4 5} \pm \mathbf{4 3 . 1 2}$ $\mathrm{mg} / \mathrm{dl}, \quad 224.32 \pm 63.47], \quad$ TG $[192.48 \pm 85.46 \mathrm{mg} / \mathrm{dl}$, $205.41 \pm 120.81]$ and LDL-C $[115.46 \pm 40.13 \mathrm{mg} / \mathrm{dl}$, $135.27 \pm 45.87]$ and this was significantly higher than in the controls (GIII) $(\mathrm{P}<0.01)$. However, the mean HDL-c value for GI \& GII was found to be $58.79 \pm 18.93 \mathrm{mg} / \mathrm{dl}$ and $53.27 \pm 18.59 \mathrm{mg} / \mathrm{dl}$. The HDLc /LDL-c ratio was calculated in GI and GII and it was found to be $(0.26 \pm 0.05 \& 0.53 \pm 0.47 \mathrm{vs} 0.56 \pm$ 0.28) which was higher than those reported in the control group. A significant difference $(\mathbf{P}<\mathbf{0 . 0 0 0 1})$ was found between patients and control population when the serum TC, TG, HDLc values, LDLc values, HDLc /LDLc ratio were compared to them. No significant differences were observed between different age categories and gender along with both patient groups and controls. Evident correlation was observed between anthropometric measurements and the lipid profile in GI and GII.
Conclusion: The study has documented several lipid abnormalities in obese type 2 diabetes mellitus and obese non-diabetic patients and has pointed to the significance of diabetic management in the control of lipid abnormalities where the control of overweight and obesity is of utmost importance. That is why in the upcoming studies we will try to detect the pattern of eating in Saudi people in Aseer Region and its relation to obesity with its subsequent. DM patients as well as obese patients are more prone to dyslipidemia which is an important risk factor for atherosclerosis and coronary heart disease so they require special attention to proper eating, and hypolipidaemic drugs to avoid associated co-morbidity of diabetes mellitus. This can be done through health education at the primary care level and the diabetic clinics.

Key words: Type 2 Diabetes Mellitus; Obesity; Dyslipidemia; Lipid Profile; BMI (Body Mass Index)

\section{Introduction}

Overweight and obesity are the main risk factor for diabetes that can be modified. Adults with obesity are many times more likely to develop diabetes mellitus than adults of a healthy weight. Currently $90 \%$ of adults with type 2 diabetes are overweight or obese (1). People with severe obesity are exposed to a high risk of developing type 2 diabetes than obese people with a lower BMI (2). There is a marked association between obesity and type 2 diabetes. The likelihood and severity of type 2 diabetes are linked with increased weight and body mass index (BMI). There is more than five times greater risk of diabetes in obese people compared to those of a healthy weight, with a threefold increase in risk for overweight people (3). It is well known that the body fat distribution is usually an important determinant of increased risk of diabetes; the precise mechanism of association remains unclear. It is really unclear why not everybody who is obese develops type 2 diabetes and why not all people with type 2 diabetes are obese $(4,5)$. Everybody with overweight or obesity is more vulnerable to have type 2 diabetes. When BMI increases, the risk of developing type 2 diabetes increases (6).

The most important environmental risk factors in T2DM patients were high caloric intake, family history, decreased physical activity and stronger multiple genetic predisposition. Obese patients have an induced insulin resistance and the mechanism of this resistance is not well known. Inflammation may be the common mediator linking obesity to the pathogenesis of diabetes (7).

Once there is obesity, the first and foremost observable changes are impaired glucose tolerance and increased insulin resistance, which result in hyperinsulinemia. This may be resulting from a combination of multiple genetic predispositions and environmental factors, that causes deranged insulin secretion (8).
Dyslipidemia is usually associated with obesity and diabetes. An increased level of plasma free fatty acids, cholesterol and triglycerides leads to deceased levels of high-density lipoprotein (HDL), and altered low-density lipoprotein (LDL) which are associated with a higher risk of cardiovascular disease (9).

The metabolic effects of subcutaneous and intra-abdominal fat are different which may be due to differences in adipose tissue distribution. It is known that abdominal fat is considered to be most likely lipolytic than subcutaneous fat. It has an unusual role in producing insulin resistance leading to diabetes mellitus. The body fatty acid release is higher in obese subjects as compared to lean subjects because of their greater fat mass (10). One of the studies found that the association between enlargement of visceral adipocytes and dyslipidemia are independent of the body composition and the fat distribution in obese subjects (11). The data collected were similar to those seen in patients suffering from type 2 diabetes. Inflammatory molecules that are produce by a lot of adipose tissue including TNF- $\alpha$, IL-6, IL-1, serum amyloid A (SAA) and adiponectin, also play an important role in the development of dyslipidemia (12).

The association of hyperglycemia with dyslipidemia affects the progression of coronary heart disease and thus increases the rate of mortality in diabetes mellitus patients. Aggressive management and control of increased lipid levels along with antidiabetic treatment not only reduces the complications of type 2 diabetes mellitus but also reduces the mortality rate (13).

Obesity is a disorder of the body regulatory system characterized by accumulation of excess body fat. It is an abnormal growth of fat cell size (hypertrophic obesity) or an increase in fat cell number (hyperplastic obesity) or a combination of both. Obese people are more likely to have high cholesterol levels; so this increases the risk of atherosclerosis (14). Obesity is important in the development of insulin resistance in metabolic 
syndrome that links with coronary heart disease. T2DM patients with dyslipidemia and obesity have markedly increased risk of coronary heart disease than dyslipidemic non diabetic obese patients (15).

Vitamin D has its unique roles other than calcium homoeostasis and bone metabolism as it has emerged linking the fat-soluble vitamin to obesity and T2DM. It appears to enhance insulin sensitivity through different mechanisms (16). The studies have found a strong link between vitamin D deficiency, obesity and metabolic syndrome. Many cross sectional and some prospective epidemiological studies have found that low serum 25(OH)D concentrations are associated with T2DM (17).

Vitamin D plays a major role in the pathogenesis and prevention of diabetes, as some evidence suggests (17). In addition, vitamin D deficiency is an independent predictor of the development of coronary artery disease in individuals with diabetes. Furthermore, another study has shown that vitamin D deficiency in diabetes may predict all causes of mortality (18).

The aim of this study was to assess the correlation between serum lipid profile as a risk factor for cardiovascular disease with other biochemical/hormonal variables, anthropometric and clinical variables among obese Type 2 diabetes mellitus and obese non-diabetic patients compared to healthy controls.

\section{Methods}

A comparative retrospective cross sectional study of obese type 2DM and obese non-diabetic patients was conducted at the Family Medicine Department, College of Medicine, King Khalid University, Abha, Saudi Arabia through data provided by Medical Specialist Center in Abha city which is allocated for chronic disease in Abha city and receives patients looking for the management of their chronic and endocrine disorders, and Diabetes Centre of Khamis Mushait Military Hospital from March 2020 to May 2020. Abha and Khamis cities constitute the central capital of Aseer region and all the citizens from all Aseer districts are pooled to these two cities for specialized medical and non-medical issues.

A total of 500 Saudi participants were categorized as follows: (200 obese Type 2 diabetic patients (T2DM) [Group I], 200 obese non-diabetic patients [Group II] and 100 healthy controls [Group III]) were randomly selected using systematic random sampling technique from March 2020 to May 2020. The demographic clinical data and medical history were recorded. The Body mass index (BMI) was considered normal if it was below $25 \mathrm{~kg} / \mathrm{m}^{2}$ and $30 \mathrm{~kg} / \mathrm{m}^{2}$ or greater was obese (19).

Fasting blood glucose, Glycosylated hemoglobin (HbAlc), and lipid profile were tested as well as other Biochemical findings such as: liver enzymes [Aspartate transaminase (AST), Alanine transaminase (ALT), alkaline phosphatase (ALP)], and kidney function tests. These biochemical findings were estimated with commercially available kits and run on AU480 Chemistry Analyzer, Beckman Coulter. Thyroid function test (Free T3, Free T4 and TSH) and vitamin D were also estimated through Access 2 immunoassay system, Beckman Coulter.
Serum lipids profile were done on a sample of blood after fasting for 14-16 hours. LDL-Cholesterol was estimated by using Friedewald formula (20) LDL-Cholesterol $=$ Total Cholesterol - (HDL cholesterol + Triglycerides/5).

The method used for determining the cholesterol and trigylcerides levels in the laboratory was the enzymatic color method. Dyslipidemia was defined according to the American Association of Clinical Endocrinologists' guidelines (21). The study was approved by the ethical board of King Khalid University in March 2020. Inclusion and exclusion criteria were involved in this study and that included (22):

Inclusion Criteria: The obese patients have been diagnosed with diabetes mellitus (GI). Obese non-diabetic group (GII), All had BMI more than $30 \mathrm{~kg} / \mathrm{m} 2$.

\section{Exclusion Criteria:}

1. Diabetic patients with overt complications including neuropathy, nephropathy, retinopathy, and ischemic heart disease.

2. Patients with acute complications like diabetic keto-acidosis, non-ketosis hyperosmolar coma and hypoglycemia.

3. Patients with coexisting illness like chronic liver disease or hypothyroidism.

4. Patients on drug therapy like diuretics, steroids, oral contraceptives and beta blockers etc.

Preformat was filled in for each patient and a full history was also taken from them. The basic anthropometric measures including: height (mts), weight $(\mathrm{kg})$ and BMI were obtained in all subjects.

\section{Statistical analysis:}

Data entry and data analysis were done using SPSS version 24 (Statistical Package for Social Science). Data were presented as number, percentage, mean, standard deviation. Chi-square test and Fisher Exact test were used to compare between qualitative variables. Independent sample t-test was used to compare quantitative variables between groups. P-value was considered statistically significant when $\mathrm{P}<0.05$. Paired-T was used to compare between variables in the same group. ANOVA analysis was done to compare the mean of each parameter.

\section{Results}

This study was conducted on 200 obese type 2 diabetes mellitus patients (T2DM, GI), 200 obese non-diabetic patients (GII) and 100 age matched controls (GIII). The demographic distribution of our study population was gathered including age, sex, systolic and diastolic blood pressure (BP) and Anthropometric measures including : height $(\mathrm{cm})$, weight $(\mathrm{Kgm})$ and Body Mass Index(BMI) of the study groups as shown in (Table $1 \& 2$ ), (Figure 1).

Lipid Profile evaluation revealed that the cholesterol levels were increased $(n=154,77.0 \%)$ in obese T2DM patients (GI) and were increased also $(\mathrm{n}=122,61.0 \%)$ in obese non-diabetics (GII). The triglycerides were increased in $(n=142,71.0 \%)$ 
obese T2DM patients and $(n=108,54.0 \%)$ of the obese non diabetics showed increased values. The LDL-C levels were increased in ( $\mathrm{n}=140,70.0 \%)$ of obese patients with T2DM, where $(n=122,61.0 \%)$ of the obese non diabetics had increased values. The HDL-C levels were decreased in $(n=144,72.0 \%)$ of obese T2DM; whereas only $(n=92,46.0 \%)$ of the obese non diabetics had decreased values as shown in Figure 2.

Overall, obese T2DM patients (GI) had significantly higher total cholesterol $(224.32 \pm 63.47$ vs. $165.42 \pm 43.12 \mathrm{mg} / \mathrm{dl})$, triglycerides levels $(205.41 \pm 12.81$ vs. $110.49 \pm 52.43 \mathrm{mg} / \mathrm{dl})$, low density lipoprotein $(135.27 \pm 45.87$ vs. $102.15 \pm 34.21 \mathrm{mg} / \mathrm{dl})$ and significant decline of high density lipoprotein cholesterol $(35.27 \pm 2.59$ vs $62.71 \pm 14.89 \mathrm{mg} / \mathrm{dl})$ as compared to healthy controls, respectively. Along with the obese non-diabetic patients (GII), a significant difference was found between patients and control population when the serum total cholesterol, triglycerides, LDLc values and HDLc values were compared to them $(210.45 \pm 43.12$ vs. $165.42 \pm 43.12 \mathrm{mg} / \mathrm{dl}, 192.48 \pm 85.46$ vs. $110.49 \pm 52.43 \mathrm{mg} / \mathrm{dl}, 115.46 \pm 40.13$ vs. $102.15 \pm 34.21 \mathrm{mg} / \mathrm{dl}$ and $(58.79 \pm 18.93$ vs $62.71 \pm 14.89 \mathrm{mg} / \mathrm{dl})$.

However, the HDLc /LDLc ratio was found to be lower in GI and GII than those reported in the controls $(0.26 \pm 0.05 \& 0.53$ \pm 0.47 vs $0.56 \pm 0.28$ ).

The detailed anthropometric parameters: height in meters, weight in kilograms and body mass index (BMI) are shown in Table 2. Evident correlation was observed between anthropometric measures with lipid profile (Figures $3 \& 4$ ) (obese T2DM
(GI) : P value was $<0.05\left[\mathrm{P}=0.048^{*}, 0.025^{*}, 0.003 * *, 0.026^{*}\right]$ regarding correlation of BMI to total cholesterol, Triglycerides, HDL-C and LDL-C respectively while in obese non-diabetic patients(II), P value was $<0.05[\mathrm{P}=0.002 * *, 0.019 *, 0.042 *]$ regarding correlation of BMI to total cholesterol, Triglycerides and HDL-C respectively, while it was non-significant regarding LDL-C, P value was $>0.05(\mathrm{P}=0.108)$.

The estimated levels of lipid profile in obese type 2 diabetes (GI) and obese non diabetic patients (GII) along with fasting blood sugars and HBA1c compared to the control group (GIII) are shown in Table 3. Regarding the fasting blood sugars, it was significantly higher in GI compared to GII and III $(\mathrm{P}<0.001 * *$, $\mathrm{P}<0.000 * * *$ respectively). In both groups (II and III), the fasting blood sugar was within normal limits $(\mathrm{P}>0.05)$.

Hemoglobin A1c (HBA1c) level showed highly significant increase in GI compared to GII and the control group (GIII); although it is noticed to be increased in GII to the upper border of normality it is still within normal.

There is no significant difference all over the three groups regarding the other biochemical variables including: serum creatinine level, liver enzymes: Aspartate transaminase (AST), Alanine transaminase (ALT), alkaline phosphatase (ALP) and Thyroid function tests (free T3, Free T4 and TSH) $\mathrm{P}>0.05$ ). Regarding vitamin D estimation, it was found that there was negative significant correlation (highly significant decline) in vitamin D levels in GI and GII compared to the healthy control group (GIII) $[\mathrm{P}=0.002 * *, 0.031 *]$.

Table 1: Descriptive clinical characteristic status of the study groups

\begin{tabular}{|c|c|c|c|c|c|}
\hline \multicolumn{2}{|c|}{ Variable } & $\begin{array}{c}\text { Obese T2DM } \\
\text { group (GI) }\end{array}$ & $\begin{array}{c}\text { Obese non-DM } \\
\text { group (GII) }\end{array}$ & $\begin{array}{c}\text { Control group } \\
\text { (GIII) }\end{array}$ & $P$ value \\
\hline \multicolumn{2}{|c|}{$\begin{array}{c}\text { Age } \\
(\text { Mean } \pm S D)\end{array}$} & $55.03 \pm \mathrm{L} 6.21$ & $39.53 \pm 14.46$ & $40.80 \pm 6.89$ & $\begin{array}{c}P>0.05 \\
\text { NS }\end{array}$ \\
\hline \multirow{2}{*}{$\begin{array}{c}\text { Sex } \\
(N, \%)\end{array}$} & Male & $81(40.5 \%)$ & $75(37.5 \%)$ & $39(39.0 \%)$ & \multirow{2}{*}{$\begin{array}{c}P>0.05 \\
\text { NS }\end{array}$} \\
\hline & Female & $119(59.5 \%)$ & $125(62.5 \%)$ & $61(61.0 \%)$ & \\
\hline \multicolumn{2}{|c|}{$\begin{array}{l}\text { Systolic BP } \\
(\text { Mean } \pm \text { SD) }\end{array}$} & $138.22 \pm L 9.12^{* *}$ & $132.73 \pm \mathrm{l} 3.50^{\circ}$ & $119.80 \pm 7.70$ & $P<0.001$ \\
\hline \multicolumn{2}{|c|}{$\begin{array}{l}\text { Diastolic BP } \\
\text { (Mean } \pm S D \text { ) }\end{array}$} & $78.96 \pm 12.88^{\circ}$ & $73.61 \pm 9.13^{*}$ & $71.80 \pm 2.43$ & $P<0.05$ \\
\hline
\end{tabular}

$* \mathrm{SD}=$ Standard deviation, $\mathrm{T} 2 \mathrm{DM}=$ type 2 diabetes mellitus, $\mathrm{BP}=\mathrm{Blood}$ pressure $\mathrm{P}<0.05=$ Significant. N.S.=Non-significant 
Table 2: Anthropometric Parameters of the study groups

\begin{tabular}{|c|c|c|c|c|}
\hline Garameter & $\begin{array}{c}\text { Obese T2DM } \\
\text { group (GI) }\end{array}$ & $\begin{array}{c}\text { Obese non-DM } \\
\text { group (GII) }\end{array}$ & $\begin{array}{c}\text { Control group } \\
\text { (GIII) }\end{array}$ & $P$ value \\
\hline $\begin{array}{c}\text { Height(m) } \\
\text { (Mean } \pm \text { SD) }\end{array}$ & $159.83 \pm 9.81$ & $165.59 \pm$ L0.04 & $160.32 \pm 8.66$ & $P>0.05$ \\
\hline $\begin{array}{c}\text { Weight (Kg) } \\
\text { (Mean } \pm \text { SD) }\end{array}$ & $79.96 \pm 16.21$ & $98.47 \pm 18.94$ & $78.76 \pm L 2.89$ & $P<0.01$ \\
\hline $\begin{array}{c}\text { BMI } \\
\text { (Mean } \pm \text { SD) }\end{array}$ & $31.07 \pm 6.38$ & $37.33 \pm 7.12$ & $28.70 \pm 3.58$ & $P<0.01$ \\
\hline
\end{tabular}

SD-Standard deviation, BMI - Body mass Index, T2DM - Type2 Diabetes Mellitus, $\mathrm{P}<0.05=$ Significant.

Table 3: Lipid Profile, FBS and HBA1c in the Study Group

\begin{tabular}{|c|c|c|c|c|}
\hline Parameter & $\begin{array}{c}\text { Obese T2DM group } \\
\text { (GI) }\end{array}$ & $\begin{array}{c}\text { Obese } \\
\text { non-diabetic } \\
\text { group (GII) }\end{array}$ & $\begin{array}{l}\text { Healthy control } \\
\text { group (GIII) }\end{array}$ & P value \\
\hline $\begin{array}{c}\text { Cholesterol(mg/dI) } \\
\text { (Mean } \pm \text { SD) }\end{array}$ & $224.32 \pm 63.47$ & $210.45 \pm 43.12$ & $165.42 \pm 43.12$ & $P<0.000=\cdots$ \\
\hline $\begin{array}{l}\text { Triglycerides }(\mathrm{mg} / \mathrm{dl}) \\
\text { (Mean } \text { + SD) }\end{array}$ & $205.41 \pm 12.81$ & $192.48 \pm 85.46$ & $110.49 \pm 52.43$ & $P<0.000 * \cdots$ \\
\hline $\begin{array}{l}\mathrm{HDL}-\mathrm{C}(\mathrm{mg} / \mathrm{dl}) \\
\text { Mean } \pm \mathrm{SD}\end{array}$ & $35.27 \pm 2.59$ & $58.79 \pm 18.93$ & $62.71 \pm 14.89$ & $P<0.02^{\circ}$ \\
\hline $\begin{array}{c}\mathrm{LDL}-\mathrm{C}(\mathrm{mg} / \mathrm{dl}) \\
(\mathrm{Me} \text { ean } \pm \mathrm{SD})\end{array}$ & $135.27 \pm 45.87$ & $115.46 \pm 40.13$ & $102.15 \pm 34.21$ & $P<0.001 *$ \\
\hline $\begin{array}{l}\text { FBS }(\mathrm{mg} / \mathrm{dl}) \\
(\text { Mean } \pm \text { SD) }\end{array}$ & $170.45 \pm 12.79$ & $135.29 \pm 15.43$ & $81.31 \pm 8.45$ & $P<0.000 * \cdots$ \\
\hline $\begin{array}{c}\operatorname{HBA} 1 \mathrm{C}(\%) \\
(\text { Mean } \pm \text { SD) }\end{array}$ & $12.88 \pm 56.91$ & $5.63 \pm 0.85$ & $4.94 \pm 0.68$ & $P<0.05^{*}$ \\
\hline
\end{tabular}

Obese T2DM= obese type 2 diabetes mellitus, $\mathrm{SD}=$ standard deviation, HDL-C=high density lipoprotein, LDL-C=low density lipoprotein, FBS=fasting blood sugar, HBA1c $=$ Hemoglobin Alc, $\mathrm{P}<0.05=$ significant, NS=Non Significant, $\mathrm{S}=$ significant. 
Figure 1: Distribution of study population based upon gender

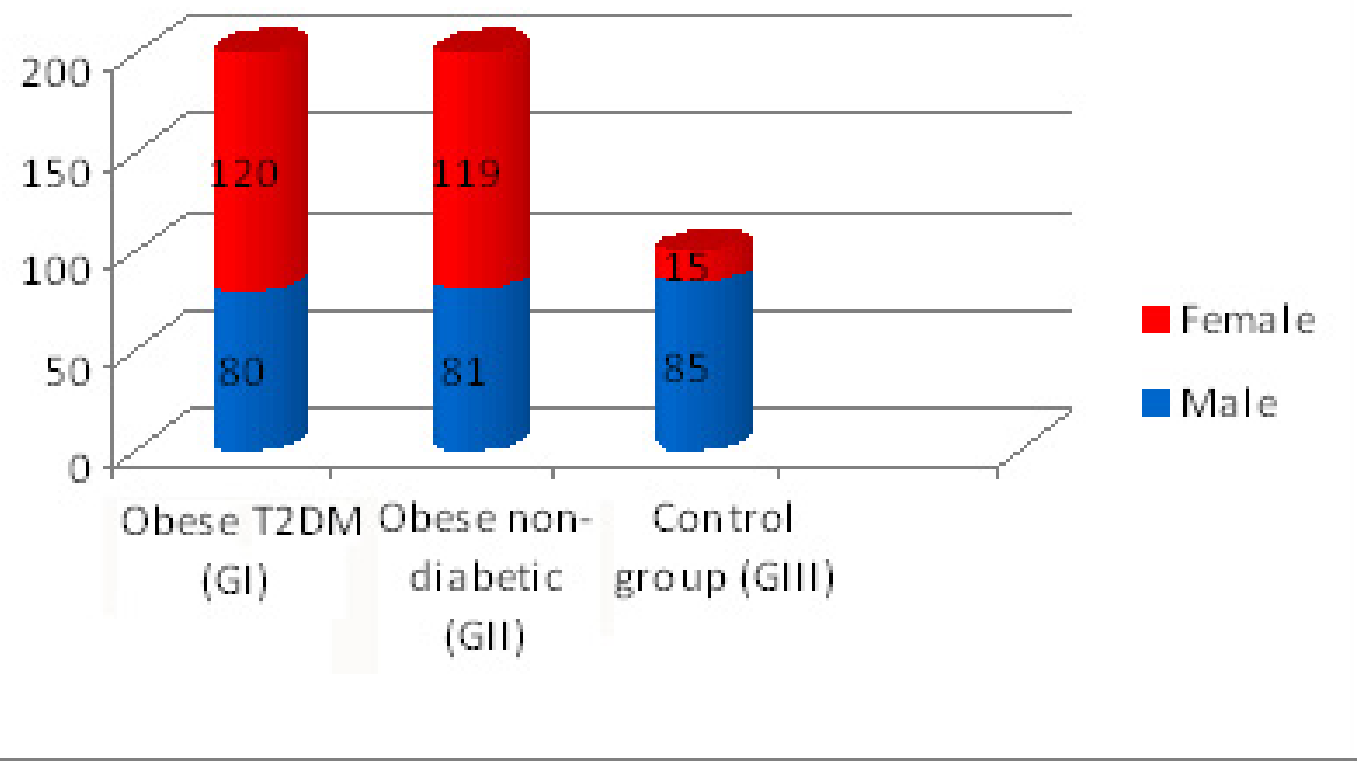

Figure 2: Distribution of study population: (Obese T2DM (GI), Obese non-diabetics (GII) and Control Group (GIII) based upon Serum Lipid Profiles level

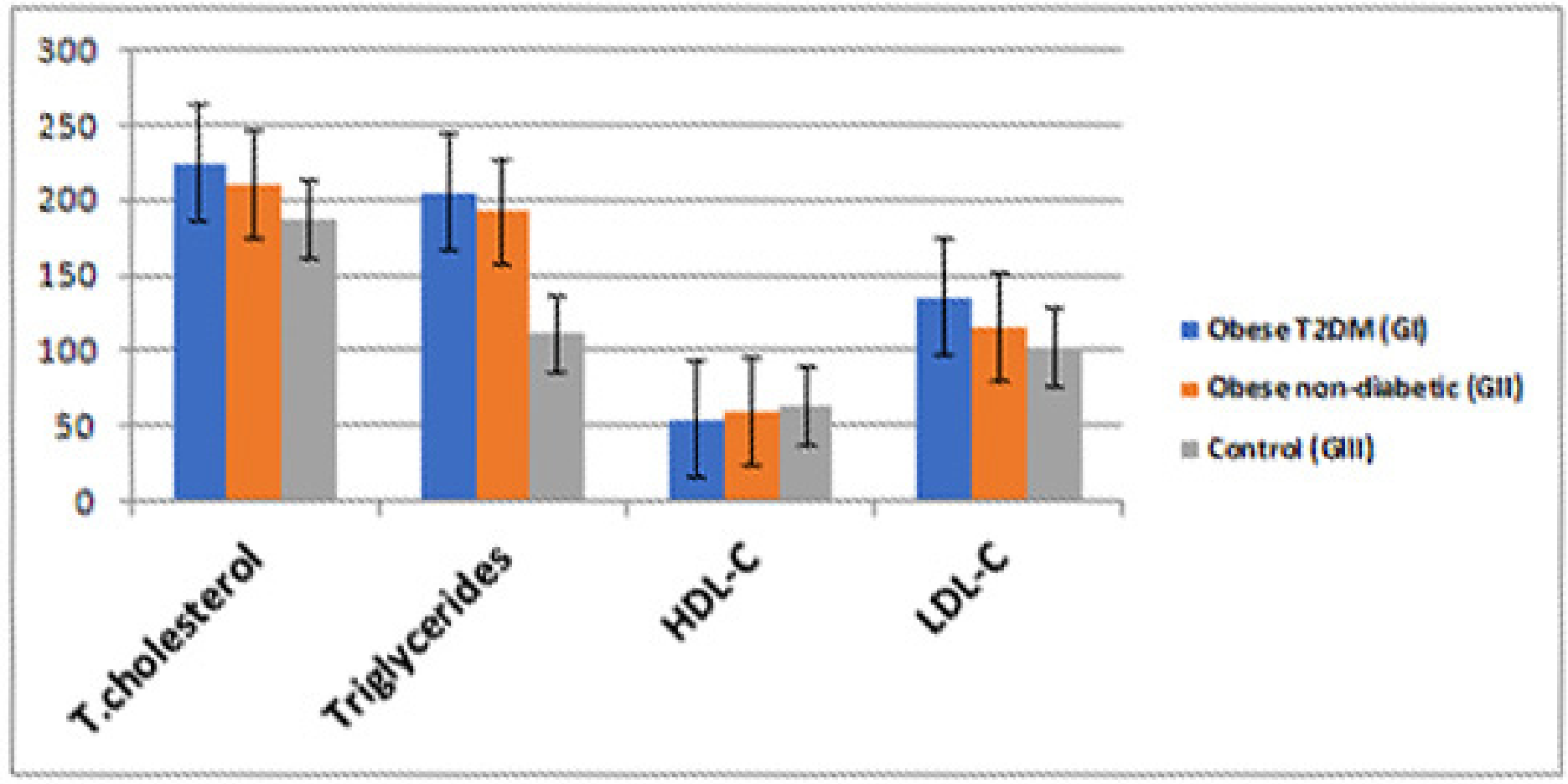

$\mathrm{DM}=$ Diabetes Mellitus HDL-C=high density lipoprotein, LDL-C=low density lipoprotein 
Figure 3: Correlation between BMI and Cholesterol (A), Triglyceride (B), HDL-C (C) and LDL-C (D) in obese-T2DM group (Group I).
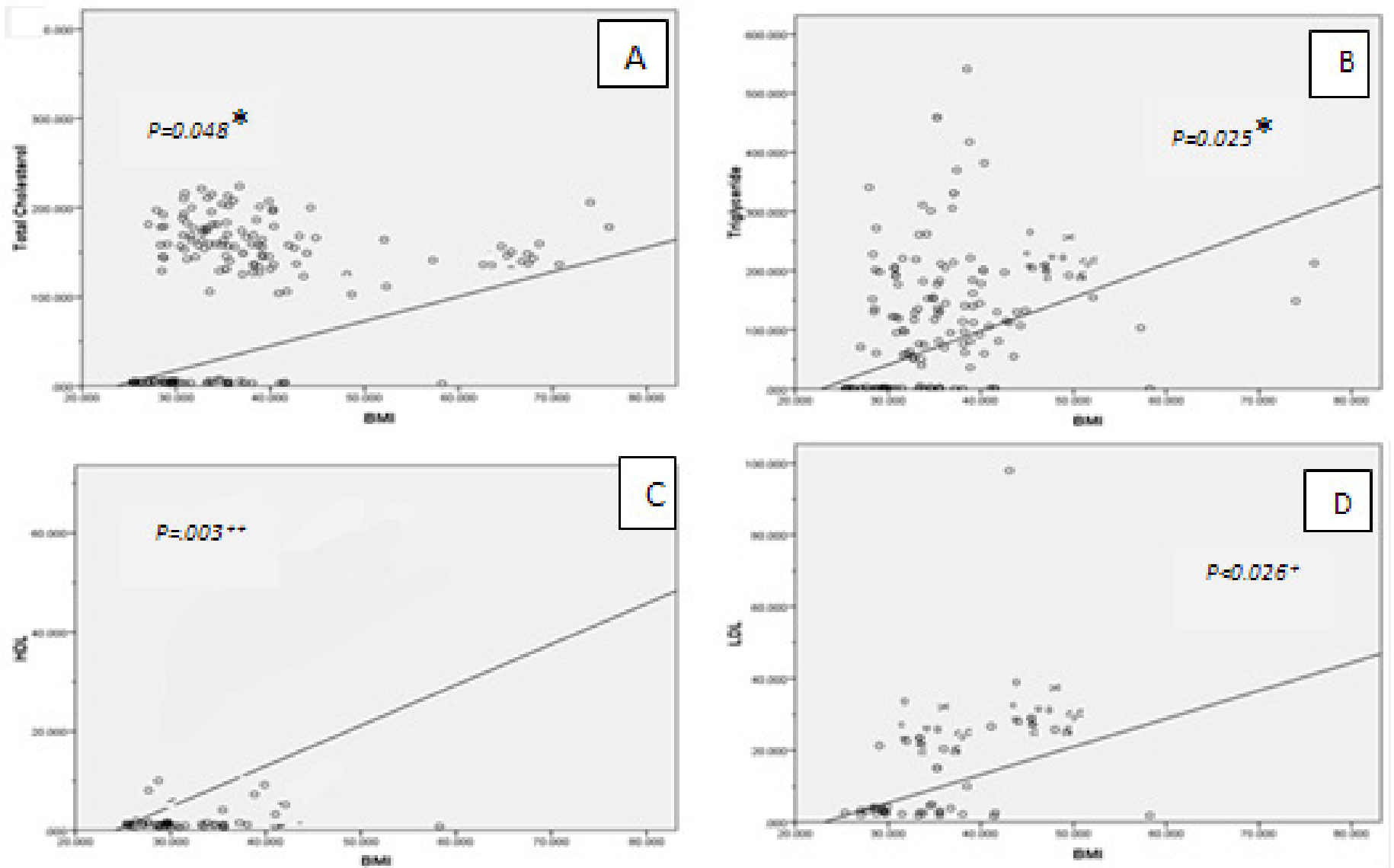

Figure 4: Correlation between BMI and Cholesterol (A), Triglyceride (B), HDL-C (C) and LDL-C (D) in obese non- diabetic patient group (Group II)
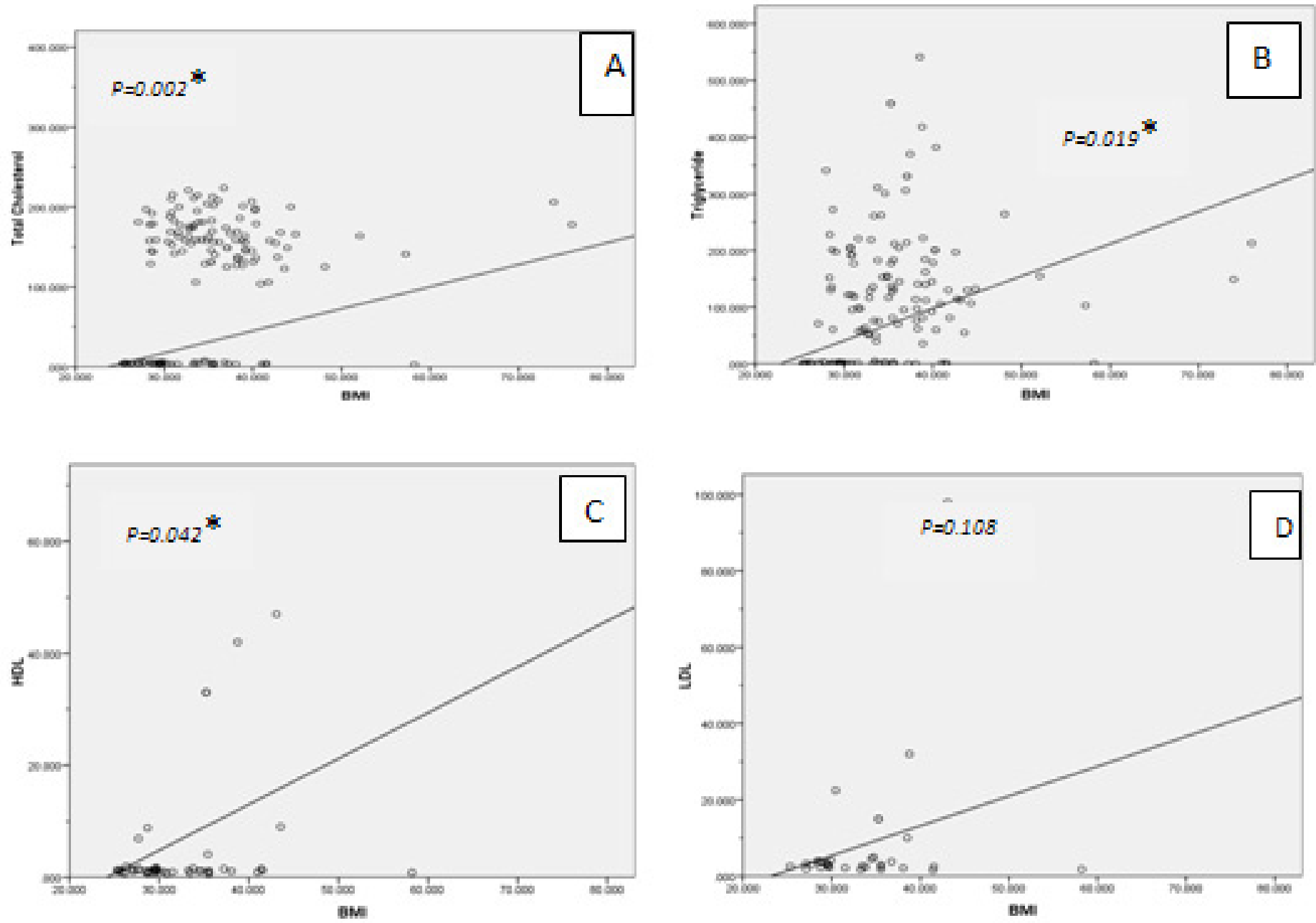


\section{Discussion}

Diabetes and obesity are chronic metabolic disorders, which are greatly increasing all over the world. They are usually accompanied by many complications which mostly lead to morbidity. Body mass index has a strong relationship to diabetes and obesity.

In our study we were trying to figure out the link between overweight and obesity condition in obese diabetic patients and obese non-diabetic patients based on the serum lipids profile in the Saudi population in Aseer Region, KSA and we were planning to discover the best ways to deal with these serious conditions through controlling the events happening in the body of these patients.

In dyslipidemia in patients with diabetes there are hypertriglyceridemia and low levels of HDL-C (23). Hypertriglyceridemia increases the risk of developing life threatening complications like diabetic ketoacidosis, coronary artery disease and lipaemia retinalis (24). It is more common in diabetics as compared to non-diabetics due to a four fold increase in VLDL triglyceride (25).

Usually type 2 diabetes mellitus and obesity are accompanied by and increased in the deposition of triglycerides in nonadipose tissue, such as skeletal muscle, liver, heart and pancreas. To define obesity, it is fat accumulation in the subcutaneous abdominal and visceral depots, and is most strongly associated with the risk of metabolic and cardiovascular complications (26). Similar to our study, some studies conducted by Santen et al. and Peret et al. observed mean serum triglyceride levels much higher in obese diabetics in comparison to obese control subject (27\&28). The relationship between obesity and T2DM is affecting anthropometric indices so that is supplying us with an effective screening and follow up for T2DM. However, the best index (BMI) for indicating the relationship between obesity and T2DM is unknown and the conclusions are not uniform (29).

Evident correlation was observed between anthropometric measures with lipid profile (obese T2DM (GI)) : P value was $<0.05\left[\mathrm{P}=0.048^{*}, 0.025^{*}, 0.003^{* *}, 0.026^{*}\right]$ regarding correlation of BMI to total cholesterol, Triglycerides , HDL-C and LDL-C respectively while in obese non-diabetic patients (GII), $\mathrm{P}$ value was $<0.05\left[\mathrm{P}=0.002 * *, 0.019^{*}, 0.042^{*}\right]$ regarding correlation of $\mathrm{BMI}$ to total cholesterol, Triglycerides and HDL-C respectively, while it was non-significant regarding LDL-C; P value was $>0.05(\mathrm{P}=0.108)$. We observed that females in both GI and GII had much increased serum total cholesterol, triglycerides and LDL-c when compared to males participating in the same study. There was an increase in the level of HDL-c among females compared to males in our study and this is good evidence of the positive effect of estrogen in increasing HDL level, as was previously studied (30).

Cardiovascular disease associated with atherogenic dyslipidemia is the more increasing risk to be developed in patients with type 2 diabetes. This signifies individuals having diabetes and those with obesity are more susceptible to develop cardiovascular disease than control individuals. It has been well documented that high levels of cholesterol and LDL play an important role in the development of arteriosclerosis and hence coronary artery disease (22). Dyslipidemia is one of the common associations in T2DM as well as in obese non diabetics and the reported prevalence of dyslipidaemia varied from 25 to $60 \%$ (31). Hypercholesterolemia and hypertriglyceridemia, High LDL-C, Low HDL-C and low HDL-C/LDL-C ratio were highly significant in this study in both obese diabetic and obese non-diabetic groups compared to the control group $[\mathrm{P}<0.001, \mathrm{P}<0.01, \mathrm{P}<0.05, \mathrm{P}<0.001)$. These values did not differ significantly from the obese non diabetic patient group (GII)[ $\mathrm{P}>0.05)$.

This is consistent with the study of Jain Darshna, et al who showed that hypertriglyceridemia predisposes the patients to life threatening complications like diabetic ketoacidosis, coronary artery disease and lipaemia retinalis (26). In the study of Gambhir et al, there was low HDL-C which was considered as an independent risk factor for occurrence of premature coronary artery disease (28). Many studies have strongly suggested an inverse correlation of HDL-cholesterol level with the development of ischemic heart disease (29).

Similar studies of D Sharma and A Jain observed increase in the levels of serum total lipids, total cholesterol, serum triglycerides and serum phospholipids in diabetic subjects as compared to normal controls (32). While Yadav NK et al observed Serum HDL - cholesterol levels did not differ significantly $(\mathrm{P}>0.05)$ in the two study groups but levels were low in obese diabetics compare to obese controls (33).

Genetic or acquired hypercholesterolemia is considered as an independent CHD risk factor. It is estimated that of most of the total heart diseases, about $56 \%$ may be caused by hypercholesterolemia (>200 mg/dl) alone (34).

Our study showed that there was no apparent sex variation in the prevalence of increased lipid profile regarding obese T2DM as well as obese non-diabetic patients group; with only a slight increase in the female group A study by Nalchjavani and other authors found that all types of dyslipidemia were significantly more prevalent in females (35).

Modern therapy of patients with diabetes demands that the physician aggressively treats lipids to reduce the high risk of cardiovascular disease in this susceptible population and in those with very high triglycerides to reduce the risk of pancreatitis (36\&37).

In the current study, increased TG concentrations are consisten tly accompanied by low HDL concentrations that often coexist with the elevated plasma glucose levels. This is in agreement with Shabana et al, who found that a high amount of sugar in plasma (hyperglycemia) results in the transfer of cholesterol esters from HDL-C to VLDL particles (38).

Apparently healthy individuals should get their lipid profiling done once or twice a year and go for appropriate lifestyle changes so as to prevent the onset of metabolic aberrations (39). 


\section{Conclusion}

In this study we reported that obese type 2 diabetes mellitus patients and obese non-diabetic patients have almost similar serum lipid profile levels. The prevalence of both obesity and type 2 diabetes continues to rise in Aseer region, KSA, along with associated direct patient care costs and wider costs to society. The purpose of this study is to describe the relationship between obesity and type 2 diabetes based on lipid profile and BMI and not to review treatment options and setting plans for further studies. Those groups of patients have well established risk factors for cardiovascular diseases. Realizing that most of the diabetics and obese have a high probability of developing cardiovascular and cerebrovascular disease, it is essential that in an individual who is obese and diabetic (two strong risk factors for coronary artery disease) their dyslipidemia should be properly taken care of, to reduce morbidity and mortality in diabetics.

Despite the small number of studies included, this study provided crucial insights into intervention strategies to address the emerging pandemic of obesity and T2DM among Saudi adults though more elaborate studies with increased sample size may provide more insights.

Other clinical studies worked at reducing the bad effects of these conditions; have been conducted or are undergoing trials. Detailed exploration of the metabolic and molecular basis of the disease may guide new approaches to prevent and treat these conditions since genetic predisposition plays an important role in the pathogenesis of insulin resistance.

\section{Declaration of conflicting interests:}

The author(s) declared the following potential conflicts of interest with respect to the research, authorship, and/or publication of this article: The author declare no conflicts of interest.

\section{References}

1. Gatineau M, Hancock C, Holman N, Outhwaite H, Oldridge L, Christie A, Ells L. Adult obesity and type 2 diabetes. Public Health England, 2014

2. International Diabetes Federation. Types of diabetes. Secondary International Diabetes Federation. Types of diabetes.

3. Abdullah A, Peeters A, de Courten M, et al. The magnitude of association between overweight and obesity and the risk of diabetes: a meta-analysis of prospective cohort studies. Diabetes Research \& Clinical Practice, 2010; 89(3):309-19.

4. Eckel RH, Kahn SE, Ferrannini E, et al. Obesity and type 2 diabetes: what can be unified and what needs to be individualized? Diabetes Care, 2011; 34(6):1424-30.

5. Neeland IJ, Turer AT, Ayers CR, et al. Dysfunctional adiposity and the risk of prediabetes and type 2 diabetes in obese adults. JAMA, 2012; 308(11):1150-9.

6. Adult obesity: Public Health England, 2012.

7. Hemanth Kumar BH. Relation between Type 2 Diabetes and obesity: A review. Int Jour of Biomed Res 2013; 4(8): 367-372.
8. Boden G, Chen X. (1995): Effects of fat on glucose uptake and utilization in patients with non-insulin-dependent diabetes. J Clin Invest 1995; 96:1261.

9. Khemka VK. Metabolic risk factors in obesity and diabetes mellitus: implications in the pathogenesis and therapy. Integr Obesity Diabetes. 2017; 3(3):1-4.

10. Horowitz JF, Coppack SW, Paramore D, Cryer PE, Zhao G, Klein S. Effect of short-term fasting on lipid kinetics in lean and obese women. Am J Physiol 1999; 276(2): E278-284.

11. Veilleux A, Caron-Jobin M, Noël S, Laberge PY, Tchernof A (2011). Visceral adipocyte hypertrophy is associated with dyslipidemia independent of body composition and fat distribution in women. Diabetes, 2011; 60: 1504-1511.

12. Sam S, Haffner S, Davidson MH, D, Agostino RB, Perez A, Mazzone T, et al. (2008) Relationship of abdominal visceral and subcutaneous adipose tissue with lipoprotein particle number and size in type 2 diabetes. Diabetes, 2008; 57: 2022-2027.

13 Ratna Manjula. Songa 1, N.Viswabarathi, Siddhartha K. Comparative study of lipid profile in obese type 2 diabetes mellitus and obese non diabetes, IOSR Journal of Dental and Medical Sciences, 2015; 14(11): 87-91.

14. Richard A. Harvey, Pamela C. Champe, Lippincotts Illustrated Reviews Biochemistry 3rd edition: 217- 233.

15. Misra A, Vikram NK. Insulin resistance syndrome (metabolic syndrome) and obesity in Asian Indians: evidence and implications. Nutrition, 2004; 20(5): 482-491.

16. Banerjee A, Khemka VK, Roy D, Poddar J, Roy TK, et al. Role of Serum Adiponectin and Vitamin D in Prediabetes and Diabetes Mellitus. Can J Diabetes. 2017; 41(3):259-265.

17. Gagnon C, Lu ZX, Magliano DJ, Dunstan DW, Shaw JE, et al. Serum 25-hydroxyvitamin D, calcium intake, and risk of type 2 diabetes after 5 years: results from a national, population-based prospective study (the Australian Diabetes, Obesity and Lifestyle study). Diabetes Care, 2011; 34: 1133-1138.

18. Al-Goblan AS, Al-Alfi MA, Khan MZ. Mechanism linking diabetes mellitus and obesity, Diabetes Metab Syndr Obes. 2014; 7: 587-591.

19. Joergensen C, Hovind P, Schmedes A, Parving HH, Rossing P. Vitamin D levels, microvascular complications, and mortality in type 1 diabetes. Diabetes Care, 2011; 34(5):1081-1085.

20. Garrow JS, Webster J. Quetelet's index (W/H2) as a measure of fatness. Int J Obes 1985; 9(2): 147-153.

21. Friedewald WT, Levy RI, Fredrickson DS. Estimation of the Concentration of LDL-Cholesterol. Clin. Chem 1972; 18 (6): 499-515.

22. Jellinger PS, Smith DA, Mehta AE, Ganda O, Handelsman Y, Rodbard HW, et al. American association of clinical endocrinologists' guidelines for management of dyslipidemia and prevention of atherosclerosis. Endocrine Practice 2012; 18(Suppl 1): S1.

23. Jain Darshna, Shaikh M. K. S, Jha R. K, Mittal Shilpa, Shahi Deepasha. Comparative Study of Serum Lipid Profile in Obese Type 2 Diabetic Patients with Obese Non Diabetic Patients. Journal of Evolution of Medical and Dental Sciences. 2014; 3(65): 14129-14136. 
24. Betteridge DJ. Diabetic dyslipidaemia. Diabetes Obes Metab 2000; 2(Suppl 1): S31-36.

25. Oh RC, Lanier JB. Management of hypertriglyceridemia. Am FamPhysician, 2007; 75(9): 1365-1371.

26. Arbeeny CM, Nordin C, Edelstein D, Stram N, Gibbons N, et al. Hyperlipoproteinemia in spontaneously diabetic guinea pigs. Metabolism, 1989; 38( ): 895-900.

27. Mengesha AY. Lipid profile among diabetes patients in Gaborone, Botswana. S Afr Med J

2006; 96(2): 147-148.

28. Oh RC, Lanier JB. Management of Hypertriglyceridemia. Am Fam Physician 2007; 75(9): 1365-71.

29. Gambhir JK, Kaur H, Gambhir DS, Prabhu KM. Lipoprotein (a) as an independent risk factor for coronary artery disease in patients below 40 years of age. Indian Heart J 2002; 52(4): 411-415

30. Aljabri K. The Relation between Overweight, Obesity and Plasma Lipids in Saudi Adults with Type 2 Diabetes. Int $\mathbf{J}$ Diabetes Clin Res, 2015; 2:3.

31. Vajo Z, Terry JG, Brinton EA. Increased intra-abdominal fat may lower HDL levels by increasing the fractional catabolic rate of Lp A-I in postmenopausal women. Atherosclerosis, 2002; 160: 495-501.

32. Betterridge DJ. Diabetic dyslipidemia. Diabetes Care, 2000; 2 (Suppl 1): 31-6.

33. Sharma D, Bansal BC, Prakash C. Serum lipid studies in the insulin dependent diabetics below the age of 30 years. J Indian Med Assoc 1970; 54 (9): 416-20.

34. Yadav NK, Thanpari C, Shrewastwa MK, Mittal RK Comparison of Lipid Profile In Type-2 Obese Diabetics And Obese Non-Diabetic Individuals. A hospital Based Study from Western Nepal. Kathmandu Univ Med J 2012; 39 (3): 44-47.

35. Abbas S, Kitchlew A, Abbas S. Disease burden of ischemic heart disease in Pakistan and its risk factors. Ann Pak Inst Med Sci 2009; 5(3):145-50.

36. Johnstone MT, Veves A. Diabetes and cardiovascular disease; 2nd edition; Chapters 7,11,15, Tumana Press, Totowa, New Jersey.

37. Feingold KR, Grunfeld C. Diabetes and Dyslipidemia, Endotext, Last Update: January 3, 2019. https:/www.ncbi.nlm. nih.gov/books/NBK305900/. Retrieved 15 June 2020.

38. American Diabetes Association. Cardiovascular Disease and Risk Management. Diabetes Care, 2019; 42 Suppl 1: S103S123.

39. Shabana H, Shahid SU, Sarwar S. The abnormal lipid profile in obesity and coronary heart disease (CHD) in Pakistani subjects. Lipids Health Dis, 2020; 19(1): 73. 